\title{
TRABALHO FAMILIAR NA PRODUÇÃO DE DENDÊ SOB CONTRATO NA AMAZÔNIA BRASILEIRA: O CASO DE SANTA MARIA, PARÁ. ${ }^{1}$ \\ FAMILY WORK IN OIL PALM PRODUCTION CONTRACTS IN THE BRAZILIAN AMAZON REGION: THE CASE OF SANTA MARIA, PARÁ. \\ TRAVAIL FAMILIAL DANS LES PLANTATIONS DE PALMIER À HUILE
SOUS CONTRAT EN AMAZONIE BRÉSILIENNE: LE CAS DE SANTA
MARIA, PARÁ.
}

TRABAJO FAMILIAR EN LA PRODUCCIÓN DE DENDÉ BAJO CONTRATO EN LA AMAZONIA BRASILEÑA: EL CASO DE SANTA MARÍA, PARÁ.

\author{
Márcia Coutinho Caetano* \\ Dalva Maria da Mota** \\ Maria do Socorro Gonçalves Ferreira**
}

RESUMO: O objetivo deste artigo é analisar as novas evidências do trabalho familiar num contexto de incentivo à especialização para o cultivo de dendê (Elaeis guineensis Jacq.). A pesquisa foi realizada por meio de um estudo de caso com observações e entrevistas na localidade Santa Maria, município de Tomé-Açu, Pará, um dos polos de produção de dendê na Amazônia brasileira. As principais conclusões são de que o trabalho familiar passa por redefinições no cultivo de dendê em decorrência: i) da intensificação do trabalho com o monocultivo do dendê em sistemas produtivos diversificados; ii) da mão de obra familiar ser insuficiente, ocasionando a necessidade de contratar assalariados para poder cumprir o contrato; iii) das mulheres dedicarem-se minoritariamente ao trabalho no dendê

\footnotetext{
$1 \mathrm{O}$ estudo faz parte das ações do Projeto AFInS - Agricultura Familiar e Inclusão Social é a sigla de um projeto de pesquisa financiado pela Embrapa sob o título Integração da Agricultura Familiar na Produção do Dendê no Pará: Possibilidade de Inclusão Social? A execução do projeto ocorre por meio de parcerias com a Universidade Federal do Pará-UFPA e Sindicatos Rurais do Nordeste paraense no período 2014/2017.* Doutora em Sociologia; Professora adjunta da Universidade Federal de Alfenas (Unifal), Alfenas, MG, Brasil; E-mail: tjdvanessa@hotmail.com

* Mestre em Agricultura Familiar; Técnica da Empresa de Assistência Técnica e Extensão Rural do Estado do Pará (Emater-PA), Belém, PA, Brasil; E-mail: mcc2010@hotmail.com

** Doutora em Sociologia, bolsista de produtividade do Conselho Nacional de Desenvolvimento Científico e Tecnológico (CNPq); Pesquisadora da Empresa Brasileira de Pesquisa Agropecuária Amazônia Oriental (Embrapa) e Professora do Programa de Pós-graduação em Agriculturas Amazônicas da Universidade Federal do Pará (UFPA), Belém, PA, Brasil; e-mail: dalva.mota@ embrapa.br *** Doutora em Desenvolvimento Sustentável; Pesquisadora da Empresa Brasileira de Pesquisa Agropecuária - Amazônia Oriental (Embrapa), Belém, PA, Brasil; e-mail: socorro.ferreira@embrapa.br
} 
e concentrarem-se nas atividades domésticas e não agrícolas; iv) da tendência de masculinização da força de trabalho sob argumento do peso da atividade em questão; e v) da permanência dos jovens no trabalho agrícola no estabelecimento familiar, contrariando tendência nacional de saída dos mesmos.

Palavras-Chave: Organização do trabalho familiar; Grupos domésticos; Divisão sexual do trabalho; Integrados.

ABSTRACT: The aim of this article is to analyze new elements relating to family work within an environment of incentives for oil palm production specialization (Elaeis guineensis Jacq.). This research involved a case study, observations and interviews in the district of Santa Maria, in the municipality of Tomé-Açu, State of Pará, Brazil, one of the main centers of oil palm cultivation in the Brazilian Amazon region. The main conclusions were that family work has been redefined through oil palm production due to: i) the intensification of the work required by the oil palm monoculture within a diversified production system; ii) the family's workforce is insufficient. Therefore, hired labor is necessary in order to comply with the contract; iii) only a minority of women are engaged in oil palm production, focusing instead on domestic tasks and non-agricultural activities; $i v$ ) the workforce is mainly male (masculinization of the workforce), given that oil palm production is considered to be heavy work; and v) young people continue to do agricultural work, in contrast to the national trend of rural exodus.

Keywords: Family Work Arrangements; Domestic Groups; Sexual Division of Labor; Integrated Workers.

$\boldsymbol{R E} \boldsymbol{S} \boldsymbol{U} \boldsymbol{M E}:$ L'objectif de cet article est d'analyser les nouvelles preuves du travail familial dans un contexte d'incitation à la spécialisation pour le palmier à huile (Elaeis guineensis Jacq.). La recherche a été réalisée au moyen d'une étude de cas avec observations et entretiens dans la localité de Santa Maria, municipalité de Tomé-Açu, état de Pará, l'un des pôles de la production d'huile de palme en Amazonie brésilienne. Les principales conclusions sont que le travail familial passe par des redéfinitions dans la culture de l'huile de palme en raison de: i) l'intensification du travail de monoculture d'huile de palme dans des systèmes de production diversifiés; ii) l'effectif familial est insuffisant, d'où la nécessité d'engager des employés pour pouvoir remplir le contrat; iii) les femmes se consacrent minoritaires au travail de l'huile de palme et se concentrent sur les activités domestiques et non agricoles; iv) la tendance à la masculinisation de la main-d'œuvre sous prétexte du poids de l'activité en question; et v) la permanence des jeunes dans le travail agricole dans l'établissement familial, contrairement à la tendance nationale à les quitter. 
Mots - clairs: Organisation du travail familial; Groupes domestiques; Division sexuelle du travail; Intégré.

RESUMEN: El objetivo de este trabajo es analizar las nuevas pruebas del trabajo familiar en el contexto del fomento de la especialización para el cultivo de palma de aceite (Elaeis guineensis Jacq.). La encuesta fue realizada a través de un estudio de caso con las observaciones y entrevistas en la localidad de Santa María, municipio de Tomé-Açu, Pará, uno de los centros de producción de aceite de palma en la Amazonia brasileña. Las principales conclusiones son que el trabajo de la familia pasa por redefiniciones en el cultivo de palma debido a: i) la intensificación de trabajo con el monocultivo de palma de aceite en los sistemas de producción diversificados; ii) la mano de obra familiar es insuficiente, lo que resulta en la necesidad de contratar a los empleados para poder cumplir con el contrato; iii) las mujeres dedicar a trabajar muy poco en el cultivo de aceite de palma y concentrarse en las actividades domésticas y no agrícola; iv) la tendencia de la masculinización de la fuerza de trabajo con la argumentación del peso de la actividad; $y$ v) la permanencia de los jóvenes en el trabajo agrícola en el establecimiento de la familia, al contrario de la tendencia nacional que es de salida de estos.

Palabras-Claves: Organización del trabajo familiar; Grupos domésticos; División sexual del trabajo; Integrados.

\section{INTRODUÇÃO}

No Brasil, o estado do Pará se destaca por ser o maior produtor de dendê (Elaeis guineensis Jacq.), cuja expansão foi intensificada nos últimos 15 anos no Nordeste Paraense (NEP). Marco determinante para este processo foi o lançamento do Programa de Produção Sustentável da Palma de Óleo (PSOP) pelo presidente Luís Inácio Lula da Silva, no Município de Tomé-Açu/PA, em 2010. Inicialmente planejado para agrocombustível, a produção paraense direciona-se para a crescente demanda da indústria de alimentos, cosméticos, fármacos etc.

Autores apontam que o incentivo à expansão da dendeicultura trouxe consigo grandes expectativas para o crescimento da economia da Amazônia (Homma; Vieira, 2012), sob o argumento das adequadas condições biofísicas da região, do aproveitamento de 
áreas consideradas degradadas (Ramalho, 2010) e pela possibilidade de geração de emprego e renda conforme previsto no Programa Nacional de Produção e Uso do Biodiesel - PNPB (Brasil, 2018).

O conjunto de potenciais vantagens do cultivo de dendê explica as políticas públicas em seu favor, as quais, por sua vez, acabam por também se constituírem como estímulo à disseminação da cultura (Becker, 2010). Entretanto, existem preocupações quanto ao seu impacto na Amazônia. Shiraishi Neto (2011) chama a atenção para os impactos dos grandes projetos sobre as demais atividades, áreas e atores ancestrais não tão intensamente atrelados aos processos de globalização. Butler e Laurance (2009) problematizam que a agricultura do dendê é uma nova ameaça ambiental nessa região. Para esses autores, os exemplos da Malásia e Indonésia demonstram que a expansão da dendeicultura pode ocorrer à custa da supressão de florestas nativas e de desestruturação de direitos tradicionais de povos autóctones, a exemplo do que mostra o estudo de Julia e White (2012) na Indonésia, onde as mulheres perderam o acesso à terra.

No âmbito da ação do Estado para dar suporte à atividade dendeicultora, destaca-se o PNPB, que tem, dentre os seus objetivos, a inclusão social em cujo escopo consta a participação de agricultores familiares na produção de dendê por meio da agricultura por contrato. Para tal, os agricultores contam com um conjunto de iniciativas como financiamento ${ }^{1}$, assistência técnica e comercialização garantida para a agroindústria com a qual o contrato foi firmado (Brasil, 2018). As agroindústrias que atuarem com agricultores familiares, teriam vantagens previstas no selo combustível social (Brasil, 2018)2 ${ }^{2}$ Não obstante, a iniciativa não foi adotada no Estado do Pará, que em 2017 não tinha nenhuma agroindústria com o Selo Combustível Social em decorrência do destino principal da produ-

1 É concedido financiamento bancário a agricultores e agricultoras familiares para a produção do dendê com contrato de integração pelo Programa Nacional de Fortalecimento da Agricultura Familiar (PRONAF).

2 De acordo com Brasil (2018), Selo Combustível Social: "é um componente de identificação criado a partir do Decreto $\mathrm{N}^{\circ} 5.297$, de 6 de dezembro de 2004, concedido pelo MDA ao produtor de biodiesel que cumpre os critérios descritos na Portaria $\mathrm{n}^{\circ} 512$, de 5 de setembro de 2017. O Selo confere ao seu possuidor o caráter de promotor de inclusão social dos agricultores familiares enquadrados do Pronaf. A concessão do direito de uso do Selo Combustível Social permite ao produtor de biodiesel ter acesso às alíquotas de PIS/Pasep e Cofins com coeficientes de redução diferenciados para o biodiesel, que varia de acordo com a matéria-prima adquirida e região da aquisição, incentivos comerciais e de financiamento". 
ção não ser o mercado de agrocombustíveis, mas o de alimentos, a distância das usinas processadoras, dentre outras razões.

Mediante tal conjunto de políticas, agricultores e agricultoras optaram por se integrar ${ }^{3}$ por meio de contratos com as agroindústrias de dendê na região de Tomé-Açu, município reconhecido pela diversificação produtiva em estabelecimentos familiares (culturas alimentares - hortaliças, frutíferas etc.), incluindo sistemas agroflorestais (SAFs), como também pela iniciativa de comercialização associativa via cooperativa.

Partimos do pressuposto de que a integração às empresas de dendeicultura tem influenciado significativamente na organização do trabalho familiar, assim como na forma de produzir. Estudos mostram que a expansão da dendeicultura no NEP instiga os agricultores a priorizarem o trabalho na dendeicultura em detrimento das outras culturas, inclusive aquelas que eram rotineiras na composição das roças (Silva et al., 2011). Mais recentemente, Mota et al. (2015) demonstraram que $24 \%{ }^{4}$ dos agricultores já não tinham culturas alimentares nos seus estabelecimentos sob o argumento de que necessitavam se dedicar exclusivamente ao dendê, especialmente pela carência de mão de obra e por causa dos compromissos contratuais.

Em Tomé-Açu, foram detectadas a diminuição das culturas alimentares nos estabelecimentos e transformações na organização do trabalho, com a maior dependência da contratação de mão de obra (Ribeiro, 2016; Sampaio, 2014). Desse modo, nos estabelecimentos familiares prioriza-se o monocultivo de dendê e questiona-se modelos precedentes.

Tendo em conta o debate, o objetivo deste artigo é analisar a organização do trabalho em estabelecimentos de agricultores que cultivam dendê na localidade de Santa Maria, Município de Tomé -Açu/Pará. A nossa hipótese é de que o modo de cultivar dos agricultores sofreu mudanças, particularmente quanto ao ritmo e en-

\footnotetext{
3 "Integrada" refere-se à pessoa agricultora de base familiar que tem um contrato de produção de dendê com uma empresa processadora (Glass, 2013; Instituto Observatório Social, 2013). Nesse sistema, a agroindústria se desincumbe da manutenção das estruturas de produção, mas "mantém um monopólio de exploração e de controle sobre os trabalhadores familiares" (Nogueira; Jesus, 2013, p. 127), inclusive quanto aos itinerários técnicos para a produção segundo padrões previamente estabelecidos e, normalmente, dependentes de crédito para ser posto em prática.

4 De um grupo de 162 agricultores integrados entrevistados nos municípios de Acará, Aurora do Pará, Capitão Poço, Concórdia do Pará, Ipixuna do Pará, Irituia, São Domingos do Capim, Tailândia, Mãe do Rio, Moju e Tomé-Açu.
} 
volvimento de membros da família, evidenciando-se a tendência de masculinização da força de trabalho.

Estruturamos o artigo em cinco partes, além da introdução, quais sejam: 1) Trabalho na dendeicultura; 2) A pesquisa; 3) Os grupos domésticos que cultivam dendê; 4) Os sistemas produtivos e os estabelecimentos familiares; 5) A organização do trabalho familiar sob a influência do cultivo do dendê; e 6) Conclusões.

\section{TRABALHO NA DENDEICULTURA}

Estudos sobre o trabalho familiar na produção de dendê são raros e quando privilegiam a agricultura familiar, trazem o tema do trabalho apenas secundariamente. No âmbito internacional, análises realizados nos maiores produtores de dendê do mundo, Indonésia e Malásia, têm destacado a coexistência de plantation e de cultivos sob regime de produção familiar com influências recíprocas em se tratando da ocupação da mão de obra. Grosso modo, há preferência pela contratação de homens em empregos ocasionais na plantation porque eles têm mais facilidade para vivenciarem a migração considerando que as mulheres estão culturalmente responsabilizadas pela esfera doméstica e, assim, deverão permanecer nos lugares de residência (Arndt et al., 2011; Julia; White, 2012; Li, 2014; Norwana et al., 2011).

Os reflexos dos arranjos familiares entre membros que "saem" e que "ficam" incidem na "feminização" da agricultura de alimentos e das atividades de coleta de produtos da biodiversidade, com maior carga de trabalho para as mulheres que ainda são responsáveis pelas crianças e idosos. Os recursos aportados pelos migrantes subsidiam a reprodução social dos grupos domésticos (GD) que persistem nos seus lugares de origem, como também observado na região canavieira do Brasil (Menezes, 2017).

No Pará, poucos estudos têm analisado o trabalho familiar e assalariado na dendeicultura. Recentemente, três pesquisadoras debruçaram-se especificamente sobre esta problemática em estudos de caso em dois municípios no NEP. Ribeiro (2016) analisou as influências da dendeicultura no trabalho de famílias que têm diferentes relações (com e sem contrato com a agroindústria para à produção 
de dendê) com a atividade, constatando que, independente do grau de envolvimento, todas as famílias vivenciam transformações no cotidiano do trabalho, quer seja porque dependem de contratação de trabalhadores para cumprir os itinerários técnicos, quer seja porque parte dos seus membros optam por se assalariar nos monocultivos empresariais. A autora mostra que o mercado de trabalho local se caracteriza pela intersecção entre trabalho familiar e assalariado.

Em outro estudo de caso, Caetano (2017) se debruçou exclusivamente sobre famílias que produzem dendê sob contrato com uma agroindústria. Ela concluiu que os arranjos de trabalho se diversificam com a insuficiência de mão de obra familiar para atender aos requisitos do itinerário técnico e, assim, há maior dependência de trabalhadores assalariados.

Partindo da constatação de que na produção de dendê no Pará predominam os homens adultos, não obstante as mulheres constarem como titulares legais de $20 \%$ dos contratos, Nascimento (2017) estudou a influência da titularidade do contrato com a agroindústria para a produção de dendê na autonomia de mulheres. A autora constatou transformações no cotidiano do trabalho com participação significativa das mulheres somente nas etapas de plantio e adubação. Entretanto, não identificou influência significativa na autonomia delas, considerando que no grupo pesquisado apenas 3 mulheres de um total de 30 faziam a gestão do cultivo. Não obstante, para todas as mulheres titulares de contrato, há importante aprendizado social em decorrência da necessidade de contato com atores de mundos sociais diferentes, como agentes de banco e da assistência técnica e da burocracia das empresas.

As constatações das três autoras não divergem significativamente daquelas internacionais, particularmente quanto à masculinização das atividades na produção de commodity e a feminização na produção de culturas alimentares e na realização das atividades no entorno da residência. A diferença reside no fato de que estes fenômenos (masculinização e feminização) evidenciam-se nos estabelecimento familiares e nos seus arredores sem ter incidido na desagregação dos GDs, cujos membros persistem vivendo na mesma residência. 
Grosso modo, o aprofundamento da divisão do trabalho entre homens e mulheres reitera a associação entre a produção de valor de troca no estabelecimento, vinculada aos homens, e valor de uso na residência, vinculada às mulheres. Na prática, as evidências empíricas mostram que algumas das residências têm se transformado em espaços de agregação de valor de produtos agrícolas (polpas de frutas) sob a responsabilidade das mulheres, paralelo a maior incidência do assalariamento delas fora das localidades onde vivem. Tais evidências, mostram que diversificam-se os arranjos quanto à ocupação dos diferentes membros adultos dos GDs.

Em todos os estudos, as análises sobre o trabalho familiar têm evidenciado transformações que incidem na intensificação da segmentação dos membros da família entre os que trabalham nas atividades agrícolas, os que trabalham em atividades não-agrícolas e os que não trabalham (as crianças). Tal intensificação tem relação direta com a interferência externa provocada pelas diretrizes quanto a quem é apto a trabalhar na dendeicultura (adultos da mesma família e trabalhadores regularmente contratados). A interferência, amparada em legislação vigente e diretrizes da Organização Internacional do Trabalho (OIT), contrapõe-se ao conteúdo tradicionalmente atribuído ao trabalho familiar que incorporava a participação de diferentes membros dos grupos domésticos segundo arranjos que consideravam idade, sexo e geração em consonância com objetivos de socialização ocupacional e de formação do caráter e das condições objetivas de reprodução social do grupo.

No Pará, os autores têm chamado a atenção para o argumento do peso do trabalho, exigências do itinerário técnico do dendê e à capacidade para lidar com agentes bancários e da agroindústria. como definidores dos que trabalharão na dendeicultura ou não, com os homens adultos predominando na atividade. A desconstrução da naturalização da diferença entre homens e mulheres foi analisada por Nascimento (2017) ao demonstrar que há mulheres que realizam todas as atividades na dendeicultura.

Há que se considerar que o plantio e a colheita são consideradas as práticas mais pesadas. Entretanto, o compromisso legal 
quanto ao cumprimento do contrato implica na reorganização do trabalho e no uso do tempo para cumprir o itinerário técnico que não é de domínio de todos os membros do GD. Ademais, há ampliação do uso da contratação para a realização de todos os tratos culturais, no momento adequado, em decorrência da não disponibilidade de mão de obra no GD (Sampaio, 2014).

Como resposta, mesclam-se diferentes iniciativas para a contratação de trabalhadores como cooperativas de trabalho e um consórcio. As primeiras, enfrentaram muitos problemas trabalhistas com o recorrente acionamento a justiça do trabalho por todos aqueles trabalhadores que se consideraram lesados. Mais recentemente, foi formado um consórcio de trabalhadores que atende uma área específica de integrados a uma empresa afiliada a Mesa Redonda sobre Óleo de Palma Sustentável (RSPO) ${ }^{5}$ e, como tal, tem exigências restritas.

Subjetivamente, está em processo a construção de um imaginário que reforça a divisão do trabalho entre campo e casa, mas vai além porque indica os aptos e os não aptos para o trabalho agrícola, contrariando o padrão de socialização produtiva e moral em exercício até recentemente na agricultura familiar. No âmago da problemática está a relativização da autonomia na gestão do estabelecimento familiar.

\section{A PESQUISA}

A pesquisa foi realizada na localidade Santa Maria, km 33 da PA 140, Município de Tomé-Açu, NEP (Mapa 1). Muito embora se trate administrativamente de apenas uma localidade, internamente, há uma subdivisão que espelha outras diferenças entre os membros do grupo que ali reside. A extensão territorial de Santa Maria é de 21 $\mathrm{km}$ ao longo da estrada. Tal distância incentivou a divisão do local 5 "Para avançar nas discussões sobre os aspectos ambientais e sociais relacionados à palma, foi criada no final da primeira década do ano 2000 a Mesa Redonda do Óleo de Palma Sustentável (Roundtable on Sustainable Palm Oil) - RSPO. Trata-se de um fórum internacional que reúne representantes de toda a cadeia produtiva do óleo de palma, além de ONGs e especialistas interessados no tema. A RSPO desenvolveu uma série de critérios ambientais e sociais a serem cumpridos pelas empresas, condição que as tornam aptas a receber o Certificado de Óleo de Palma Sustentável (CSPO). Devidamente aplicados, esses critérios ajudam a reduzir os impactos negativos do cultivo do óleo de palma no meio ambiente e nas comunidades locais. Entre os critérios estão a redução do uso de agrotóxicos e queimadas, tratamento justo aos trabalhadores, dentre outros. Por isso essa certificação deve ser estimulada pelo setor e perseguida por todos os produtores que almejam atingir o patamar da sustentabilidade" (Abrapalma, 2018). 
em Santa Maria e em Nossa Senhora da Conceição com 37 e 21 GDs, respectivamente. Nas duas localidades, têm habitantes descendentes dos primeiros posseiros que ali chegaram nos anos 60 .

Após estabelecerem-se localmente, dois grupos disputavam os eventos católicos para que fossem mais próximos às suas moradias em decorrência do povoamento ter se dado à margem da estrada e se tratar de uma grande extensão para ser percorrida a pé. Para lidar com a questão, chegaram a um consenso, e a localidade ficou dividida em duas partes com eventos em cada uma delas. Mesmo assim, todos que ali residem insistem que não se tratam de duas localidades e, nesse discurso, explicitam o sentimento de pertencimento a um mesmo território.

Santa Maria está constituída por 58 GDs (e 48 casas) ${ }^{6}$, cujos membros desenvolvem atividades agrícolas (cultivos diversos), criam pequenos animais e assalariam-se. Somente a partir de 2010, com o incentivo de políticas do governo federal, 10 agricultores dessa localidade firmaram contrato de produção com uma agroindústria e implantaram cultivos de dendê no sistema de integração.

Para a pesquisa, privilegiamos as abordagens qualitativa e quantitativa com levantamento de dados primários e secundários. Um estudo de caso foi realizado em Santa Maria. Os procedimentos constaram de entrevistas (estruturadas e não diretivas) com os primeiros residentes e com homens e mulheres que ali habitam e trabalham na agricultura, dentre os quais, os responsáveis pelo contrato para a produção de dendê que são todos homens. Observações da vida cotidiana foram realizadas nos diferentes espaços do estabelecimento e da localidade.

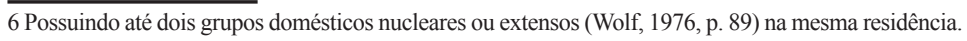


Mapa 1 - Localização de Santa Maria em Tomé-Açu - Estado do Pará

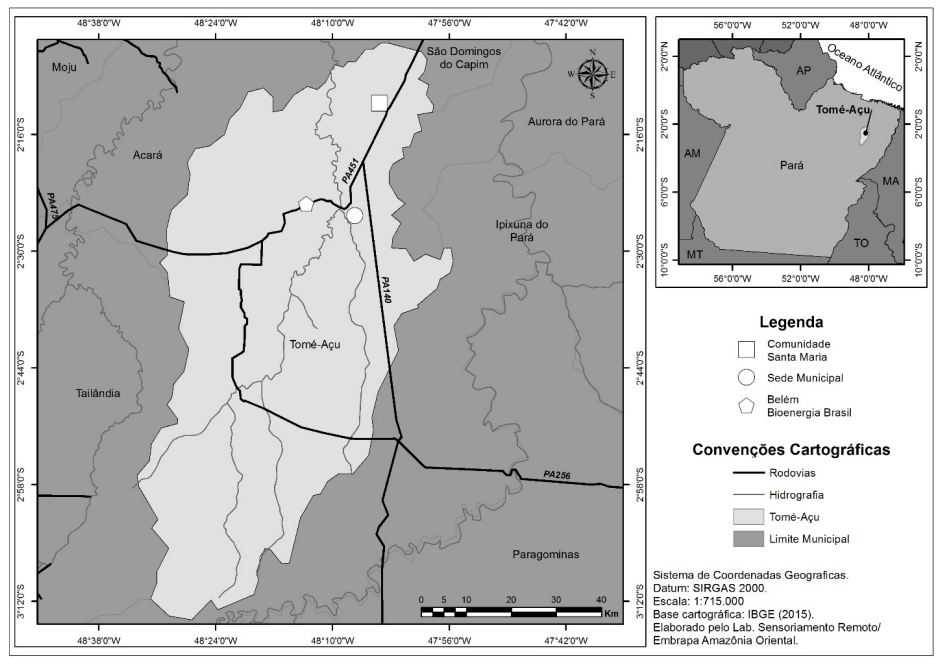

As reflexões realizadas neste artigo amparam- se nas contribuições da sociologia rural e do trabalho e na antropologia social. Os principais conceitos que iluminam o debate são: trabalho familiar, divisão sexual do trabalho e integração.

\section{OS GRUPOS DOMÉSTICOS QUE CULTIVAM DENDÊ}

Privilegiamos em nossa análise os GDs, muito embora os discursos dos entrevistados reportem-se sempre à família e suas diferenciações. O termo família e grupo doméstico expressam princípios organizacionais distintos: o primeiro está associado ao parentesco, o segundo está intimamente relacionado aos preceitos residenciais, bem como as ações desenvolvidas "num espaço comum” (Yanagisako, 1979 apud Afonso, 2000, p. 157). Desse modo, compactuamos com as análises de Fortes (1974), que diz que "a fábrica, por assim dizer, da reprodução social é o grupo doméstico", sendo o responsável tanto pela sua reprodução física como social (Fortes, 1974, p. 3). 
Sob esta compreensão, classificamos os 10 grupos domésticos estudados em 3 tipos: nuclear (5 grupos), extenso (4 grupos) e chefiado pela avó (1 grupo), conforme exposto no quadro abaixo.

Quadro 1: Tipos de grupos domésticos dentre os que têm contrato de integração.

\begin{tabular}{|c|c|c|}
\hline Grupos Domésticos (GD) & Constituição & $\begin{array}{c}\mathbf{N}^{\mathbf{0}} \text { de Grupos } \\
\text { Domésticos }\end{array}$ \\
\hline Nuclear & Casal e filhos biológicos & 05 \\
\hline Extenso & Casal, filhos biológicos e parentes & 04 \\
\hline Chefiado por avó & Avó e netos & 01 \\
\hline \multicolumn{2}{|c}{ Total } & 10 \\
\hline
\end{tabular}

Fonte: Pesquisa de Campo 2016.

Em Santa Maria, os GDs têm um total de 59 pessoas, com um número médio de 6 membros por grupo, maior do que os 4,2 indicados pelo Instituto Brasileiro de Geografia e Estatística - IBGE - para a região Norte (Ibge, 2014) e equivalentes aos números identificados por Mota (2014) em quatro outras localidades do NEP.

Estudo realizado no NEP encontrou que "[...] na quase totalidade dos casos evidências indicam que o grupo doméstico extenso consiste numa residência temporária de filhas casadas ou com uniões consensuais que habitam com os pais provisoriamente [...]" (Mota, 2014, p. 306). Os nossos dados diferem, considerando que a maioria é do tipo nuclear, e que $40 \%$ são extensos. Também encontramos um grupo doméstico distinto desta definição, que é chefiado pela avó, pois suas filhas residem em outros locais, mas ela se ocupa dos netos.

Os GDs em análise têm um quantitativo de 3 membros em $30 \%$ dos casos, 4 em 20\%, 5 em 10\%, 7 em 20\% e mais de 10 membros em $20 \%$. Na sua maioria, os GDs estão na "fase de expansão, que vai desde o casamento de duas pessoas até a completa formação de sua família de procriação" (Fortes, 1974, p. 3).

Em se tratando do trabalho, aproximadamente 39\% dos membros dos GDs se ocupam na agricultura. Dentre os demais, há idosos, crianças e aqueles que trabalham exclusivamente na esfera doméstica ou como assalariados (somente duas mulheres). 


\section{OS SISTEMAS PRODUTIVOS E OS ESTABELECIMEN- TOS FAMILIARES}

A memória oral registra que a vida social em Santa Maria baseava-se em relações amparadas no parentesco e na vizinhança. As unidades de produção, segundo indicam, persistem como lugar de vida e de trabalho dos que se reconhecem como pertencentes àquele território, muito embora as relações entre os que ali residem e os citadinos tenham se intensificado.

Para efeitos analíticos, demarcamos três grandes fases na história do grupo. Uma primeira, após a chegada e a posse da terra nos anos 1960, na qual predominavam a floresta, cultivos anuais (mandioca, feijão e arroz) no sistema de corte e queima e quintais ${ }^{7}$ com fruteiras. $\mathrm{O}$ trabalho era realizado exclusivamente pelos membros dos GDs e pelos mutirões incentivados pela igreja católica no seu trabalho de evangelização. Uma segunda fase, na qual a pimentado-reino e as fruteiras se ampliaram para além do quintal, paralelamente à diminuição da floresta, até os anos 2000. Nos últimos anos, a oscilação do preço da pimenta influenciou sobremaneira no uso da terra, paralelamente à coexistência com as demais culturas. O cultivo da pimenta é um marco quanto ao início da contratação ocasional de trabalhadores considerando que a colheita demanda muita mãode-obra, qual seja, cerca de 72 horas de trabalho por pessoa.

A precariedade de acesso aos serviços de apoio à produção e as dificuldades de comercialização foram determinantes para que 10 agricultores optassem pela dendeicultura em 2010. Um grupo de técnicos de uma agroindústria realizou uma reunião em Santa Maria para a divulgação das vantagens da agricultura sob contrato quanto ao acesso à assistência técnica, crédito, mercado garantido e renda. O procedimento assemelha-se aquele analisado por Gomes e Magalhães (2016) em São Domingos do Capim/PA, onde diferentes instituições e atores locais somaram forças para divulgar as vantagens da dendeicultura para os agricultores que viessem a se integrar e para o município como um todo.

7 São aqui considerados quintais as áreas adjacentes às residências, com criações de pequenos animais, cultivos de frutíferas, hortas e plantas medicinais principalmente para uso doméstico. 
Após a reunião em Santa Maria, rede de informações se constituíram para ponderar o advento da dendeicultura. As informações veiculadas pelos técnicos coincidiam com os comentários quanto ao sucesso da produção por agricultores familiares em municípios vizinhos. Não obstante a informação de grande parte dos agricultores quanto às vantagens financeiras, eles preferiram observar as primeiras experiências de integração localmente para tomarem uma decisão posteriormente.

Após decisão quanto a assinar o contrato, os técnicos da empresa visitaram os estabelecimentos e selecionaram áreas que, segundo os agricultores, "já fossem desmatadas". Providências foram tomadas para fazer o Cadastro Ambiental Rural (CAR), o contrato com a agroindústria e o financiamento bancário. Dos 10 contratos, 9 foram assinados por homens e apenas 1 por uma jovem, filha de uma agricultora que já é aposentado e se considerou idosa para ser titular do mesmo.

As áreas e tipos de cultivos nos diferentes estabelecimentos dos 10 GDs que têm cultivos de dendê se distribuem conforme Gráfico 1.

Gráfico 1 - Áreas de cultivos e quantidade de moradores por GD

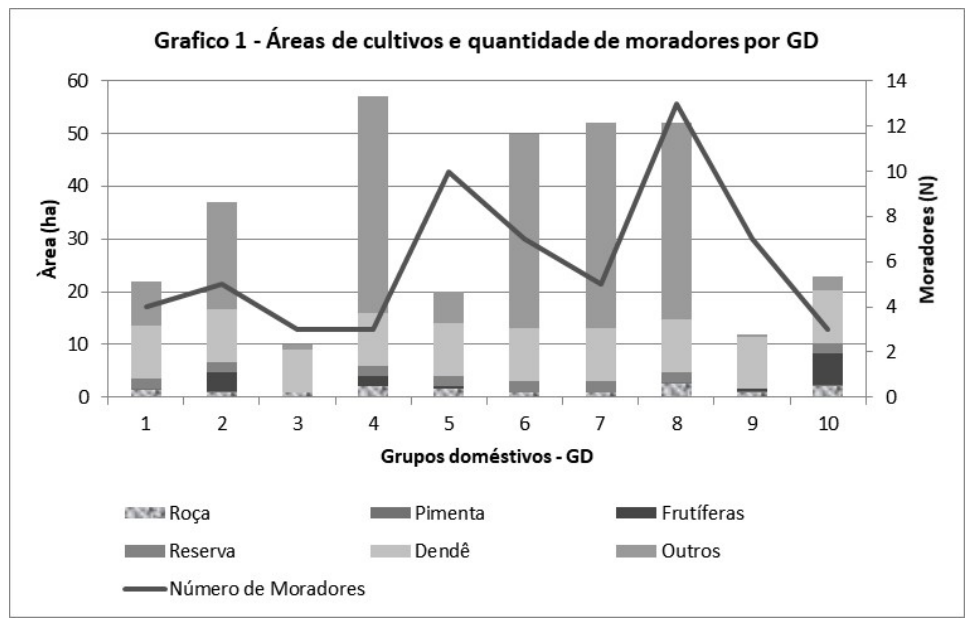

Fonte: Pesquisa de campo, 2015. 
Como pode ser observado no Gráfico acima, 5 estabelecimentos têm áreas que variam de 10 a 30 ha (GDs 1, 3, 5, 9 e 10). Somente 1 estabelecimento tem área total de 37 ha (GD2), seguindo-se de 4 com áreas entre 50 a 60 ha (GDs 4, 6, 7 e 8). A maior ou menor disponibilidade de terras está diretamente relacionada ao tempo de chegada da família e à sucessão que, muitas vezes, implica na divisão da terra entre herdeiros. Consequentemente, não há relação entre a disponibilidade de terra e o número de membros do GD.

Em se tratando do uso da terra, os sistemas de produção são relativamente diversificados com roças (mandioca, feijão e milho), frutíferas, pimenta-do-reino, dendê e criação de pequenos animais. Constatamos relação inversa entre o tamanho da área e a diversificação. Quanto menor o estabelecimento, maior a diversificação e vice-versa, relação influenciada pela disponibilidade da força de trabalho familiar. Produzir parte do que consome é estratégia usual para diminuir a dependência do mercado, para o exercício da alternatividade e também para manter vínculos sociais por meio da troca de produtos entre vizinhos (farinha e frutas são trocados por carne enlatada, peixe ou frango, conforme observamos).

Somente os GD3, GD6 e GD7 cultivam exclusivamente dendê e mandioca. Os demais GDs cultivam, além destas, pimenta-do-reino e frutíferas e também criam pequenos animais. Todos os estabelecimentos possuem área que denominamos de "outros" com usos da terra com quintais, vegetação de pousio, reservas e áreas construídas. A criação de pequenos animais se dá nas áreas dos quintais.

Para os cultivos tradicionais (roça com mandioca, milho), o tamanho das áreas informadas foram entre 1 a 2 ha. Em um estabelecimento havia 1 ha de pastagem abandonada - que foi incluído como "outros"8 - em virtude da venda do gado com posterior divisão do dinheiro entre os filhos.

Nos 10 estabelecimentos, 9 têm 10 ha exclusivamente com dendê, e apenas 1 tem 8 ha porque possui somente 10 ha de área total (GD3). A semelhança entre o tamanho das áreas plantadas com dendê contrasta com a diversidade de arranjos para as demais culturas, que pastagem abandonada cujas dimensões não foram explicitadas pelo entrevistado. 
variam em função da mão de obra familiar disponível e da estratégia de produção de cada GD. O dendê traz, no modelo que o sustenta, uma decisão externa quanto ao tamanho da área e, nesse sentido, parece homogeneizar os agricultores enquanto produtores de uma commodity. Apenas parece, porque o modo de lidar com o conjunto das culturas varia de estabelecimento para estabelecimento, não obstante o itinerário técnico a ser seguido para a produção de dendê.

Em face da novidade da dendeicultura, os discursos apontam que o dendê é considerado como uma "nova forma de produzir", associada a um itinerário técnico com insumos externos. Compreendemos que o "novo" é também relacionado às mudanças que essa cultura acarreta no interior do estabelecimento mediante os arranjos que devem ser instituídos para garantir a coexistência de diferentes cultivos com um mesmo número de membros do GD. Ou seja, os dados evidenciam que há aumento do trabalho e dependência da contratação de mão de obra para corresponder às novas exigências, que não são apenas operacionais e restritas ao estabelecimento, mas também relacionadas à negociação, relação com a agroindústria, vigilância de contrato, banco etc.

\section{A ORGANIZAÇÃO DO TRABALHO FAMILIAR SOB A IN- FLUÊNCIA DO CULTIVO DE DENDÊ}

Por trabalho familiar estamos compreendendo o domínio e exercício de práticas e saberes para a obtenção do necessário para a reprodução da força de trabalho da família (Neves, 1981). Para além dos propósitos de produção, atributo de socialização lhe é conferido por possibilitar aos membros da família o aprendizado não só de um ofício, mas também de códigos morais e de hierarquias. Na unidade de produção, essa relação é inseparável, uma vez que são os arranjos familiares que dão suporte à grande parte das atividades ali desenvolvidas. Amparados em relações de gênero, geração e ciclo de vida, o trabalho familiar quando realizado põe em prática funcionamentos e movimentos particulares em sintonia com o ciclo de desenvolvimento do grupo, do uso e da apropriação do produto final, influenciado também pelas formas de subordinação externas. 
A maior parte das atividades desenvolvidas nos estabelecimentos aqui em análise, está sob a responsabilidade dos membros dos GDs. Do total de 59 membros, 23 dedicam-se ao trabalho na agricultura, sendo 19 homens e 4 mulheres, o que representa 39\%. Dos demais, $35 \%$ são crianças e os $26 \%$ são idosos. Os demais dedicam-se a atividades domésticas e não agrícolas. A área cultivada e a mão de obra utilizada por cada GD podem ser visualizadas no Gráfico 2.

Gráfico 2 - Área, cultivos e mão de obra familiar e contratada nos estabelecimentos por GD em Santa Maria, Tomé-Açu.

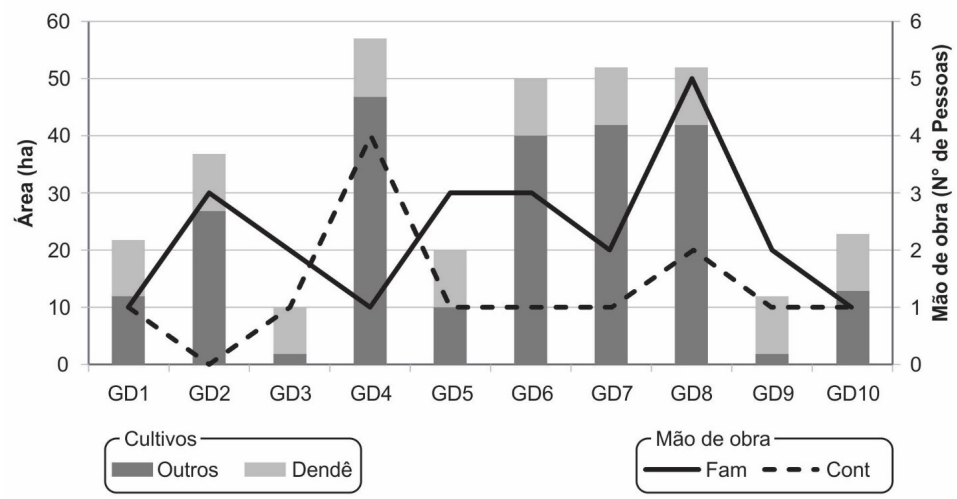

Fonte: Pesquisa de campo, 2016.

Demonstramos no gráfico à similaridade quanto às áreas com dendê. Chama a atenção que outros cultivos ocupam a maior parte da área dos estabelecimentos, com exceção do GD2. As explicações para tal fato residem predominantemente, na falta de capacidade em termos de mão de obra e capital para explorá-las. Adicionalmente, mostramos quais os arranjos que se instituem entre o trabalho familiar e assalariado para a realização das atividades na dendeicultura. A relação entre membros dos GDs e assalariados é da ordem de $65 \%$ e $35 \%$, respectivamente,

Os dados mostram que há predominância do trabalho familiar em sete GDs. Em dois, há equiparação. Em apenas um GD, não há trabalho assalariado (GD2) porque tem a menor área e uma maior 
disponibilidade de mão de obra familiar. Já no GD4, a contratação de quatro trabalhadores supera todos os demais em decorrência da disponibilidade de apenas um membro do GD para o trabalho.

A organização do trabalho nos estabelecimentos dos agricultores integrados sofreu modificações significativas com a inserção da cultura do dendê, tendo em vista o monocultivo em áreas consideradas extensas, o itinerário técnico e a coexistência do cultivo do dendê com as atividades pré-existentes. Segundo informam, o volume de trabalho do dendê interfere no funcionamento do estabelecimento como um todo e na definição de quem é considerado apto ou não para o trabalho, segundo critérios relativos ao peso do trabalho, ao domínio de novas tecnologias e a relações profissionais tecidas no exterior do estabelecimento.

Em se tratando dos membros dos GDs, grosso modo, persiste nos discursos uma divisão sexual do trabalho na qual os homens se reconhecem como responsáveis pelo estabelecimento e capazes de realizar todas as atividades na agricultura. Às mulheres são atribuídas as atividades consideradas "leves" (adubação do dendê e colheita da pimenta) e todas as demais na esfera doméstica (processamento de produtos, preparo de alimentos, cuidados com crianças e idosos etc.). Os discursos indicam que o cultivo do dendê requer força física porque o trabalho é considerado pesado. Como afirmou uma das mulheres que trabalha no cultivo do dendê:

"No dendê eu ajudei ele a plantar, jogava adubo, coroava quando era pra fazer a coroa com a enxada eu ia, mas quando era pra jogar o adubo, eu jogava também com eles, pra colher é mais pesado, ai é mais pra homem" (K.O.T., 26 anos, agricultora).

Alguns avaliam que o plantio e a colheita são as atividades mais pesadas. As atividades mais leves são o coroamento (limpeza ao redor da planta) e a adubação. Como afirmou o Sr. L. A. (agricultor, 48 anos): "Só é leve para quem tem dinheiro e possui maquinário".

As análises de Nascimento (2017) põem em questão tais assertivas ao mostrar que algumas mulheres fazem a gestão do cultivo 
e trabalham em todas as atividades da dendeicultura, mesmo que considerem que há diferença de esforço entre estas. Torres e Rodrigues (2010, p. 240) analisam que as noções de 'leve' e 'pesado' na agricultura refletem construções culturalmente determinadas e, por isso, devem ser relativizadas. Não obstante, persiste a compreensão de que o trabalho pode ser classificado em função de quem o faz, sendo consideradas leves as atividades realizadas por mão de obra feminina e infantil, conforme já criticamente analisado por Paulilo (1987). As consequências mais visíveis são a aparente falta de reconhecimento e de envolvimento das mulheres nas decisões econômicas e públicas relacionadas ao estabelecimento.

A descrição de trabalho de homem e de mulher também corrobora para atualizar a compreensão de Hirata e Kergoat (2007), que afirmam:

"A divisão sexual do trabalho é a forma de divisão do trabalho social decorrente das relações sociais entre os sexos; mais do que isso, é um fator prioritário para a sobrevivência da relação social entre os sexos. Essa forma é modulada histórica e socialmente. Tem como características a designação prioritária dos homens à esfera produtiva e das mulheres à esfera reprodutiva e, simultaneamente, a apropriação pelos homens das funções com maior valor social adicionado (políticos, religiosos, militares etc.)" (Hirata; Kergoat, 2007, p. 599).

Sob a ótica da divisão sexual do trabalho, todos os estabelecimentos contam com trabalho de homens tanto no dendê quanto em outros cultivos. Somente em quatro estabelecimentos as mulheres trabalham em todos os cultivos. Contudo, todas elas afirmam trabalhar também na esfera doméstica e nas atividades necessárias ao bem estar da família e no processamento de produtos, realizando a denominada conciliação:

"Tem o serviço de casa e o serviços da roça, eu ajudo a prantar, a capinar, só não roçar, que a 'roçação' é com os homens, por isso que digo: se a gente parar pra pensar e ver, a mulher trabalha mais que os homens, farinha! É mais eu que faço, antigamente era pior tor- 
rar farinha, antes nem era no motor, era no ralo, né, ralava mandioca no ralo, eu ia na roça, arrancava mandioca, vinha pro retiro, raspava, só eu e Deus, não tinha filho, não tinha ninguém, ralava tudinho, torrava num dia um saco de farinha, agora eu não dou mais conta de fazer isso não. Eu faço, mas não é como antes, ainda vou arrancar na roça, mas o resto não, não faço. Eu vou pra roça cedo, umas 6:30; 7:00h, quando sol esquenta já quero tá de volta, lá pelas 9:00h” (E.O.S., 39 anos, agricultora).

Mesmo que conciliem trabalhos em casa e trabalhos na roça, a fala refere-se ao trabalho da mulher como "ajuda". Esta última condição remete aos princípios indicados pelas autoras quanto à separação e hierarquia que indicam que existem trabalhos de homens e trabalhos de mulheres, e que um trabalho de homem "vale" mais que um trabalho de mulher (Hirata; Kergoat, 2007, p. 599).

Como tal, aos homens é atribuído o lugar de representação da família e do estabelecimento, cabendo-lhes todos os contatos com técnicos, agentes de bancos e representantes de agroindústrias associados à esfera da produção. Analisamos que em consequência da falta de protagonismo, algumas mulheres têm buscado novas carreiras, como é o caso de duas delas, que trabalham como assalariadas em atividades não agrícolas (uma como professora e a outra como servente em escolas próximas da localidade) e de uma jovem que trabalha em uma loja na cidade. Ademais, constatamos em outro município que as mulheres muitas vezes discordam do endividamento do grupo familiar porque conhecem experiências frustradas tanto quanto à obtenção de crédito para produzir uma cultura que não produz um alimento que possa ser consumido diretamente quanto ao uso do solo por tanto tempo com uma cultura permanente e dependente de uma única empresa.

Adicionalmente, há contratação de assalariados (diaristas) em 90\% dos estabelecimentos exclusivamente para o trabalho na dendeicultura, especialmente no período do coroamento e a colheita que realiza-se quinzenalmente.

Observando os dados sobre os sistemas de produção, em apenas um GD não há contratação de assalariados, considerando que três membros dedicam-se exclusivamente ao trabalho na agricultura. Importante 
observar que todos os GDs que contam com o trabalho das mulheres dependem menos da contratação de diaristas (GDs 2, 3, 6 e 7). Analisamos que elas contribuem para suprir a lacuna do trabalho que seria executado por homens, o que nos leva a questionar o discurso quanto a segmentação entre trabalho de homens e de mulheres naquele contexto.

Apesar da constatação, o trabalho na dendeicultura é predominantemente realizado pelos homens e por isso, os diaristas contratados são jovens homens, confirmando a tendência de masculinização da força de trabalho na dendeicultura.

No trabalho de coexistência de diferentes cultivos, a organização do trabalho se reorganiza e distribui-se no tempo tendo a quinzena como referência para o dendê e a semana para as demais culturas que abastecem as feiras locais semanalmente. Em consequência, o próprio trabalho é redefinido porque uma das culturas exige obediência e prazos- que constam como uma das condições especificadas no contrato - a um protocolo técnico estruturado externamente. Essa condição influencia para que seja dedicado um maior tempo ao cultivo do dendê do que às outras culturas que não estão sob controle externo e que dependem do pagamento de um financiamento relativamente alto quando comparado a outros cultivos.

Em se tratando dos jovens, diferenças importantes coexistem pautadas nas desigualdades de gênero e consequentemente nas diferentes oportunidades que terão dentro e fora do estabelecimento. Assim, os jovens homens se concentram no trabalho no estabelecimento em conciliação com o estudo. Em apenas um GD um dos jovens homem optou por sair de casa para morar na cidade e trabalhar como assalariado na agroindústria de dendê com perspectivas de melhoria de suas condições financeiras. As jovens mulheres, entretanto, se concentram no trabalho doméstico em conciliação com o estudo, e apenas uma delas saiu de casa para se dedicar ao trabalho assalariado.

Independentemente da idade, as mulheres têm menor participação nas atividades mais distantes das residências e as crianças já não são envolvidas em função da repressão ao trabalho infantil pelas razões já explicitadas. Tudo isso implica em mudanças quanto à socialização dos mais jovens, agora mais restrita à esfera doméstica: 


\begin{abstract}
"Se for falar o serviço de casa nunca acaba, a gente levanta de manhã e faz café, aí já vou cuidar, tem os bichos pra mim dá de comer: galinha, porco, levanto vou lavar louça, varrer casa, ainda mais que os meninos estuda tudinho, aí de manhã fica só eu aqui, tenho que fazer tudo sozinha, a louça eu lavo de noite, quando todo mundo acaba de jantar já deixo a louça toda lavada, quando as meninas tão por aí, elas ajudam, lavam, varre e passa pano na casa” (M.S.S., 37 anos, agricultora)
\end{abstract}

Nesse quadro, a socialização para o trabalho na agricultura sofre uma ruptura e as crianças não aprenderão os saberes e as práticas subjacentes ao ofício de agricultor. Mediante tal mudança, outros modos de socialização são postos em prática com maior centralidade da escola e de participação em redes sociais como facebook e whatsap.

Com todas as mudanças, persistem as conclusões de Garcia Junior (1983, p. 59) quanto aos membros do GD executarem predominantemente as atividades no estabelecimento a partir de uma divisão do trabalho em que nem todos realizam "de tudo". Diferenças quanto às atividades e papéis que desenvolvem se alicerçam em gênero e idade. Mesmo assim, os GDs atuam não apenas como "um grupo estruturado cercado por condições históricas e culturais, mas como o conjunto de normas e valores que ele agrega através de uma rede de relações e representações sociais" (Carneiro, 1998, p.65).

\title{
7 CONCLUSÕES
}

O objetivo do artigo foi analisar as evidências do trabalho familiar num contexto de incentivo à especialização para o cultivo de dendê em Santa Maria, Município de Tomé-Açu no NEP. A hipótese de que o ritmo e o modo de cultivar dos agricultores sofreram mudanças com a predominância de homens no cultivo, foi confirmada.

Constatamos que o ritmo, volume, peso e a apreciação sobre o trabalho familiar são os indicadores mais relevantes para a qualificação das mudanças relativas ao trabalho naquele contexto.

Em se tratando do ritmo e volume de trabalho na dendeicultura, concluímos que a distribuição das atividades ao longo da semana 
aumentaram com repercussão nos demais cultivos que ficam dependentes da disponibilidade de mão de obra. Influenciam neste aspecto tanto o aumento da área cultivada com um itinerário técnico considerado novo para os agricultores, quanto a colheita do dendê ser atrelada ao calendário da empresa cujo caminhão recolhe os frutos em dias previamente agendados. Assim, o ritmo de trabalho é mais intenso e ditado, simultaneamente, por um itinerário e uma agenda definidos externamente pela empresa.

No geral, concluímos que na produção de dendê há prevalência do trabalho familiar, com o envolvimento de homens nos 10 estabelecimentos e das mulheres em 4 deles. As crianças estão ausentes do trabalho em atendimento a diretrizes externas, o que significa uma ruptura com o padrão tradicional de socialização para o trabalho.

O peso do trabalho é um demarcador para as atividades de homens e mulheres, muito embora haja contraste entre o discurso e as evidências no que diz respeito à divisão sexual do trabalho. Os homens predominam nas atividades agrícolas, com participação das mulheres em $40 \%$ dos casos, ainda que associadas ao trabalho considerado "leve". Concluímos que nos GDs onde as mulheres trabalham na dendeicultura há menor dependência da contratação de terceiros porque as mulheres suprem parte importante do que fariam os contratados. Assim, atestamos a atualidade dos princípios da separação e da hierarquia na divisão social do trabalho porque apesar da importância da presença das mulheres na esfera agrícola, ela é minimizada.

Transformações foram também evidentes na divisão sexual do trabalho entre os jovens. Há maior envolvimento dos rapazes nas atividades agrícolas e das jovens nas atividades domésticas e em outras atividades fora do estabelecimento. Os jovens membros dos GDs envolvidos na pesquisa predominam no trabalho agrícola localmente, contrariando tendências confirmadas nacionalmente quanto à saída do campo por parte destes (Balsadi; Del Grossi, 2016).

$\mathrm{Na}$ grande maioria dos estabelecimentos $(90 \%)$ há dependência da contratação ocasional de trabalhadores para trabalhar exclusivamente na colheita do dendê, condição que tem colocado os titulares de contrato sob tensão mediante as diretrizes da empresa 
que pressiona por alternativas de legalização, desafio árduo em um contexto de prevalência da informalidade.

As principais conclusões mostram que o cultivo do dendê influenciou na reorganização do trabalho nos estabelecimentos familiares, conforme previsto. Entretanto, a reorganização tem incidido nas subjetividades quanto à importância das culturas alimentares versus commodity, com a prioridade de alocação da mão de obra nesta última, por um lado. Por outro, tem influenciado na avaliação de quem é apto ou não para o trabalho na agricultura familiar segundo diretrizes externas que extrapolam a tradição e que colocam novos desafios quanto às ocupações dos filhos dos agricultores e agricultoras no futuro.

\section{REFERÊNCIAS}

ABRAPALMA. Iniciativas internacionais. Mesa Redonda para Óleo de Palma Sustentável (RSPO) e Grupo de Inovadores no Óleo de Palma (POIG). In: http://www.abrapalma.org/pt/iniciativasinternacionais-2/, acesso em 10 de fevereiro de 2018.

AFONSO, A. I. Grupo doméstico e mudança social: abordagens quantitativas e qualitativas. Etnográfica. Vol. 4, nº. 1, pp. 153-182, 2000.

ARNDT, C.; BENFICA, R.; THURLOW, J. Gender implications of biofuels expansion in Africa: the case of Mozambique. World Development. Vol. 39, nº 9, pp. 1649-1662, 2011.

BALSADI, O. V.; DEL GROSSI, M. E. Trabalho e emprego na agricultura brasileira: um olhar para o período 2004-2014. Revista de Politica Agrícola. Vol. 25, n 4, pp. 82-96, 2016.

BECKER, B. K. Recuperação de áreas desflorestadas da Amazônia: será pertinente o cultivo da palma de óleo (Dendê)? Confins. $\mathrm{n}^{\circ}$ 10, 2010. In: http://confins.revues.org/6609, acesso em 14 de março de 2014.

BRASIL. Secretaria Especial de Agricultura Familiar e do Desenvolvimento Agrário. O que é o Programa Nacional de Produção e Uso do Biodiesel (PNPB)? In: http://www.mda.gov. $\mathrm{br} /$ sitemda/secretaria/saf-biodiesel/o-que-\%C3\%A9-o-programanacional-de-produ $\% \mathrm{C} 3 \% \mathrm{~A} 7 \% \mathrm{C} 3 \% \mathrm{~A} 30$-e-uso-do-biodiesel-pnpb, acesso em 05 de janeiro de 2018.

BUTLER, R. A.; LAURANCE, W. F. Is oil palm the next threat to the Amazon? Tropical Conservation Science. Vol. 2, $\mathrm{n}^{\mathrm{o}}$ 1, pp. 1-10, 2009.

CARNEIRO, M. J. Camponeses, agricultores e pluriatividade. Rio de Janeiro: Contracapa Editora, 1998. 228 p. 
COUTINHO, M. C. A organização do trabalho familiar sob a influência do cultivo do dendê na comunidade Santa Maria/Tomé-AçuPará. 2017. Dissertação (Mestrado em Agriculturas Familiares e Desenvolvimento Sustentável) - Universidade Federal do Pará, Belém, PA, $127 \mathrm{p}$.

FORTES, M. O Ciclo de desenvolvimento do grupo doméstico. Brasília, DF: Ed. da UnB, 1974. 9 p.

GARCIA JÚNIOR, A. Terra de trabalho: trabalho familiar de pequenos produtores. Rio de Janeiro: Paz e Terra, 1983. 236 p.

GLASS, V. Expansão do dendê na Amazônia brasileira: elementos para uma análise dos impactos sobre a agricultura familiar no nordeste do Pará. São Paulo: Repórter Brasil, [2013]. 15 p.

GOMES, L. S.; MAGALHÃES, S. B. Agricultores integrados do dendê e questões relativas ao sistema de produção no PA, Terra Nova. EcoDebate, 2016. In:

https://www.ecodebate.com.br/2016/05/30/agricultores-integrados-dodende-e-questoes-relativas-ao-sistema-de-producao-no-pa-terranova-por-lucinaldo-soares-gomes-e-sonia-barbosa-magalhaes/, acesso em 10 de fevereiro de. 2018.

HIRATA, H.; KERGOAT, D. Novas configurações da divisão sexual do trabalho. Caderno de Pesquisa. Vol. 37, no 132, pp. 595-609, set./ dez. 2007. In: http.scielo.br/pdf/cp/v37n132/a0537132, acesso em 20 de julho de 2014.

HOMMA, A. K. O.; VIEIRA, I. C. G. Colóquio sobre dendezeiro: prioridades de pesquisas econômicas, sociais e ambientais na Amazônia. Amazônia Ciência e Desenvolvimento. Vol. 8, nº 15, pp. 79-90, jul./dez. 2012.

IBGE.Cidades@: Pará: Aurora do Pará. In: http://www.cidades.ibge.gov. br/ xtras/perfil.php?lang=\&codmun=150095\&search=para|aurorado-para, acesso em 11 de agosto de 2014.

INSTITUTO OBSERVATÓRIO SOCIAL. O comportamento sóciotrabalhista na produção do óleo de palma do dendê no Estado do Pará com foco nas empresas Agropalma, Biovale/Biopalma, Petrobras Combustiveis. São Paulo, 2013.

JULIA; WHITE, B. Gendered experiences of dispossession: oil palm expansion in a Dayak Hibun community in West Kalimantan. Journal of Peasant Studies. Vol. 39, n 3-4, pp. 995-1016, July-Oct. 2012.

LI, T. M. The gendered dynamics of Indonesia's Oil Palm labour regime. Singapore: Asia Research Institute, 2014. 17 p. (Working Paper Series, n. 225).

MENEZES, M. A. Agricultores expropriados: terra, migrações e trabalho. In: DELGADO, G. C.; 
BERGAMASCO, S. M. P. P. Agricultura familiar brasileira: desafios e perspectivas de futuro. BrasíliaDF: Ministério do Desenvolvimento Agrário, 2017. pp. 418-433.

MOTA, D. M. da et al. Produção de culturas alimentares e dendê nos estabelecimentos familiares no Nordeste paraense. In: SEMINÁRIO INTERNACIONAL AMÉRICA LATINA: POLÍTICA E CONFLITOS CONTEMPORÂNEOS, 2015, Belém, PA. Anais... Belém, PA: GETTAM: NAEA: UFPA, 2015. pp. 119-125.

MOTA, D. M. Família e grupos domésticos na Amazônia paraense. Cadernos de Ciência \& Tecnologia. Vol. 31, nº 2, pp. 289-314, maio/ ago. 2014.

NASCIMENTO, D. A. S. do. Trabalho e autonomia em campo de domínio masculino: mulheres que têm contratos de produção com agroindústrias de dendê em São Domingos do CapimPA. 2017. Dissertação (Mestrado em Agriculturas Familiares e Desenvolvimento Sustentável) - Universidade Federal do Pará, Belém, PA, $136 \mathrm{p}$.

NEVES, D. P. Lavradores e pequenos produtores de cana: estudo das formas de subordinação dos pequenos produtores agrícolas ao capital. Rio de Janeiro: Zahar editores, 1981. 212 p.

NOGUEIRA, C. M.; JESUS, E. de. A pequena produção avícola familiar e o sistema de integração no oeste catarinense: "uma prisão de portas abertas". Caderno CRH. Vol. 26, n 67, pp. 123-138, jan./abr. 2013.

NORWANA, A. W. A. B. D. et al. The local impacts of oil palm expansion in Malaysia: an assessment based on a case study in Sabah State. Bogor, RI: CIFOR, 2011. 26 p.

PAULILO, M. I. S. O peso do trabalho leve. Ciência Hoje. Vol. 5, n 28, pp. 64-70, jan./fev. 1987.

RAMALHO, A. et al. Relatório técnico do zoneamento agroecológico do dendezeiro para as áreas desmatadas da Amazônia Legal. Rio de Janeiro: Embrapa Solos, 2010. 44 p.

RIBEIRO, L. B. O trabalho sob a influência da dendeicultura em vilas rurais paraenses. 2016. Dissertação (Mestrado em Agriculturas Familiares e Desenvolvimento Sustentável) -Universidade Federal do Pará, Belém, PA, 120 p.

SAMPAIO, I. C. A agricultura familiar e a agroindústria do dendê em Tomé-Açu (PA): efeitos da agricultura por contrato na produção e no trabalho familiar. 2014. Dissertação (Mestrado em Sociologia e Antropologia) - Universidade Federal do Pará, Belém, PA, 205 p.

SHIRAISHI NETO, J. Novos movimentos sociais e padrões jurídicos no processo de redefinição da região amazônica. In: SHIRAISHI NETO, J. et al. (Org.). Meio ambiente, território e práticas jurídicas: enredos em conflito. Manaus: EDUFMA, 2011. pp. 23-52. 
SILVA, F. L.; HOMMA, A. K. O.; PENA, H. W. A. O cultivo do dendezeiro na Amazônia: promessa de um novo ciclo econômico na região. Observatorio de la Economía Latino americana, $\mathrm{n}^{\circ}$ 158, 2011. In: http://www.eumed.net/cursecon/ecolat/br/, acesso em 26 de maio de 2016.

TORRES, I. C.; RODRIGUES, L. M. O trabalho das mulheres no sistema produtivo de várzea amazônica. In: SCOTT, P.; CORDEIRO, R.; MENEZES, M. (Org.). Gênero e geração em contextos rurais. Santa Catarina: Ed. Mulheres, 2010. pp. 235-254.

WOLF, E. R. Sociedades camponesas. Rio de Janeiro: Zahar, 1976. 150 p. 